\title{
Migration of Mesenchymal Stem Cells of Bursal Tissue after Rotator Cuff Repair in Rats
}

\author{
Elem Safi $^{1 *}$ Andreas Ficklscherer ${ }^{1 *}$ Maryna Bondarava ${ }^{1}$ Oliver Betz ${ }^{1}$ Anja Zhang ${ }^{1}$ \\ Volkmar Jansson ${ }^{1}$ Peter E. Müller ${ }^{1}$ \\ ${ }^{1}$ Department of Orthopedic Surgery, Physical Medicine and \\ Rehabilitation, University Hospital of Munich, Munich, Germany \\ Joints 2018;6:4-9. \\ Address for correspondence Elem Safi, MD, Department of \\ Orthopedic Surgery, Physical Medicine and Rehabilitation, University \\ Hospital of Munich, Campus Grosshadern, Marchioninistrasse 15, \\ Munich 81377, Germany (e-mail: elem.safi@med.uni-muenchen.de).
}

\begin{abstract}
Purpose The purpose of this study is to verify migration of mesenchymal stem cells of bursal tissue into the healing site after rotator cuff repair in rats.

Methods Fischer rats and green fluorescent protein (GFP)-transgenic rats were used. Bursal tissue from GFP rats was isolated and transplanted into tendon repair sites in Fischer rats. We examined the histology of the rotator cuff and the proportion of GFPpositive cells in the repaired rotator cuff 1,3 , and 6 weeks after surgery.

Keywords

- bursal tissue

- rotator cuff

- mesenchymal stem cells

- cell migration

- rats

Results Cell migration was observed during the third and sixth week after surgery. We also found mesenchymal stem cells and formed bursal cluster patterns in the repaired rotator cuff tendons.

Conclusion Mesenchymal stem cells migrated from bursal tissue and infiltrated the repaired rotator cuff tendons.

Clinical Relevance Mesenchymal stem cells from bursal tissue can contribute to the healing progress of the repaired rotator cuff.
\end{abstract}

\section{Introduction}

Rotator cuff tear (RCT) is one of the most common degenerative diseases of the upper extremity. RCTs take up to $30 \%$ of the population aged older than 65 years. ${ }^{1-4}$ Considering the sustained growing and aging population, RCTs are expected to be increasing rapidly. ${ }^{5}$

Treatment options for RCTs vary between conservative and surgical procedures. Surgical intervention is indicated by persistent pain after failed conservative treatment of at least 6 months or in the case of acute injuries. The established surgical procedures, ranging from open to arthroscopic repair, ${ }^{6}$ focus on the main objective of increasing strength at the repair site to prevent rerupture. The development of these techniques has improved steadily over the last decades and demonstrated good results in pain relief and increased function of the shoulder. ${ }^{6-10}$

${ }^{*}$ Both the authors contributed equally to this article.
Nevertheless, Bishop et $\mathrm{al}^{6}$ showed that $31 \%$ of mini-open rotator cuff repairs and $47 \%$ of arthroscopic repairs failed to heal or had another tear by the time of the follow-up examination. At clinical examination, patients with failed rotator cuff repair presented with decreased strength in forward elevation and external rotation. Several other studies showed high rates of RCT repair failure. ${ }^{9-12}$

Contradictory evidence about the effect of subacromial bursal tissue as part of the rotator cuff is present in the current literature. Reports on the presence of mesenchymal stem cells (MSCs) are the main topics of several current studies. ${ }^{13-17}$ Nourissat et al ${ }^{14}$ found that MSC injection into the destroyed enthesis of the Achilles tendon led to regenerative healing in terms of an organized enthesis with columnar chondrocytes in a rat model. Another study claimed that synovial cells from the subacromial bursa in patients with RCTs are superior cell sources in vitro, suggesting that those MSCs could be considered for biological augmentation and used in rotator cuff repair. ${ }^{17}$ 
We conducted the present study to verify the presence of MSCs into the bursal tissue and migration of MSCs from bursal tissue to repair site in a rat rotator cuff repair model. We hypothesized that bursal tissue would increase histological and biomechanical function of repaired rotator cuff.

\section{Methods}

\section{Study Design and Experimental Groups}

A rat model as recommended by Soslowsky et $\mathrm{al}^{18}$ and Derwin et al $^{19}$ was used because of anatomical similarities. The Institutional Animal Care and Use Committee from District Government of Upper Bavaria approved this study (no. 55.2-1-54-2532-184-13).

Five Fischer rats (Charles River; F-344/DuGl) with a mean weight of $250 \mathrm{~g}$ and five green fluorescent protein (GFP) rats (RRRC; F344.Tg) with a mean weight of $300 \mathrm{~g}$ were used for the present study (-Table $\mathbf{1}$ ).

There was no difference in weight at arrival within the groups and at the time of surgery. To guarantee recovery from the transport and adaptation to the new environmental surroundings, animals were taken into the study not earlier than 7 days after arrival. Since the subacromial bursal tissue is macroscopically not visible in the rat model, the retrocalcaneal (also described as achilleal) bursal tissue was transplanted. ${ }^{20-22}$

\section{Surgical Technique}

The rats were anesthetized with isoflurane, followed by an injection of $60 \mathrm{mg} / \mathrm{kg}$ ketamine and $9 \mathrm{mg} / \mathrm{kg}$ xylazine, administered intramuscularly. Oxygen was given via nose cone. All surgeries were performed in sterile conditions with the rat in lateral position like described before. ${ }^{2,7}$

The hind limbs of GFP rats were skinned. The Achilles tendon was subsequently identified and sharply detached with a scalpel in the part that is 2 to $3 \mathrm{~mm}$ distal of the Achilles tendon and adjacent of the calcaneus. Bursal tissue from GFP rats was then isolated in phosphate-buffered saline (PBS) and prepared for transplantation.

Surgery for Fischer rats was started in lateral position with shaving of the right shoulder region. The animals were kept warm on a heating pad. Only the right shoulder was operated on, ensuring that the rats were ambulatory and could feed after surgery. The skin incision was followed by a deltoidsplitting cut. The acromioclavicular joint was divided until the rotator cuff was visible. The supraspinatus tendon was identified and sharply detached from the greater tuberosity.

Table 1 Overview of rats

\begin{tabular}{|l|l|l|}
\hline $\begin{array}{l}\text { Groups } \\
\text { (number) }\end{array}$ & Strain & Donor institution/Country \\
\hline $\begin{array}{l}\text { Group A: } \\
\text { GFP rats }\end{array}$ & GFP(F344.Tg) & $\begin{array}{l}\text { RRRC Strain Acquisition } \\
\text { Coordinator Columbia, } \\
\text { MO 65201, United States }\end{array}$ \\
\hline $\begin{array}{l}\text { Group B: } \\
\text { Fischer rats }\end{array}$ & F-344/DuGl & Charles River, Germany \\
\hline
\end{tabular}

Abbreviation: GFP, green fluorescent protein.
The tendon was dissected by a transverse cut. ${ }^{2}$ It was then reattached without any preparation of the footprint. The tendon was reconstructed and repaired with a single Mason-Allen stitch using a No. 5-0 double-armed Prolene suture (Ethicon, Somerville, New Jersey, United States) through the supraspinatus tendon. Two $0.5-\mathrm{mm}$ tunnels were drilled on the greater tuberosity, $2 \mathrm{~mm}$ from the articular surface away. The suture ends were then guided through the bone tunnels and knotted over the humeral cortex to reconnect the supraspinatus to its footprint on the greater tuberosity. Bursal tissue of GFP rats which had been prepared previously was then attached using 3-0 Ethibond sutures on the supraspinatus tendon, following the deltoid split that was closed with 3-0 Ethibond. The skin closure was performed with a 3-0 Vicryl-subcutaneous suture (Ethicon). ${ }^{2,7}$

For analgesia, the rats were given subcutaneous buprenorphine injections, containing $0.05 \mathrm{mg} / \mathrm{kg}$ body weight, at 6 and 12 hours postoperatively. ${ }^{2}$ Postoperative animal care was administered. All animals were monitored according to the guidelines provided by the Institutional Animal Care and Use Committee for discomfort, distress, and pain.

No animal was lost during the experiment or excluded from analysis. No anesthesia-related, surgery-related, or postoperative complications of any kind occurred during the study. Food intake and gait did not change because of pain or restricted shoulder function after surgery. There was no significant difference in body weight among the groups when the animals were killed.

\section{Histology}

The supraspinatus muscle, including the tendon and the adhered GFP-marked bursa achilles, was removed for histologic analyses after 7, 21, and 42 days after surgical transplantation of the bursa. For control purposes, the supraspinatus muscle of the other shoulder, including the tendon, was removed as well. Immediately after removal, the specimens were placed in PBS Buffer (Dulbecco's Phosphate Buffered Saline, PBS, Berlin, Germany) to conserve cell structure. Afterward, the specimens were covered with Tissue-Tek O.C.T. Compound (Sakura Finetek Europe B.V, Alphenaan den Rijn, The Netherlands) in Tissue-TekCryomold mold-sand and deep-frozen using liquid nitrogen. With the cryostat (Leica CM3050, Bensheim, Germany), the frozen blocks including the specimens were cut into 7 - and 10 - $\mu \mathrm{m}$-thick sections parallel to the long axis of the tendon. After drying for 1 hour, the sections were fixed in $4 \%$ neutral-buffered formalin and stained with blue-fluorescent Hoechst dye to assess the organization in relation to the tendon and the integration of the bursa achillea by displaying the cell nucleuses. For the conservatory cover, the medium Fluoromount (SERVA Electrophoresis $\mathrm{GmbH}$, Heidelberg, Germany) was used. Pictures of the bursa achillea with surrounding tissue and the tendon were recorded with an Axio Cam MRc5 camera (Zeiss, Göttingen, Germany), attached to a Zeiss Axioskop 40 fluorescent light microscope. For magnification purposes, 100x, 200x, and 400x magnifications with adapted illuminations were used. 
6 Migration of MSC of Bursal Tissue after Rotator Cuff Repair Safi et al.

\section{Results}

One week after bursal transplantation, green GFP signal was identified in the surrounding tissue. Bursal tissue of GFP rats, consisting of fat vacuoles and connective tissue, was sized as compact tissue. A migration of MSCs was not observed (-Fig. 1).

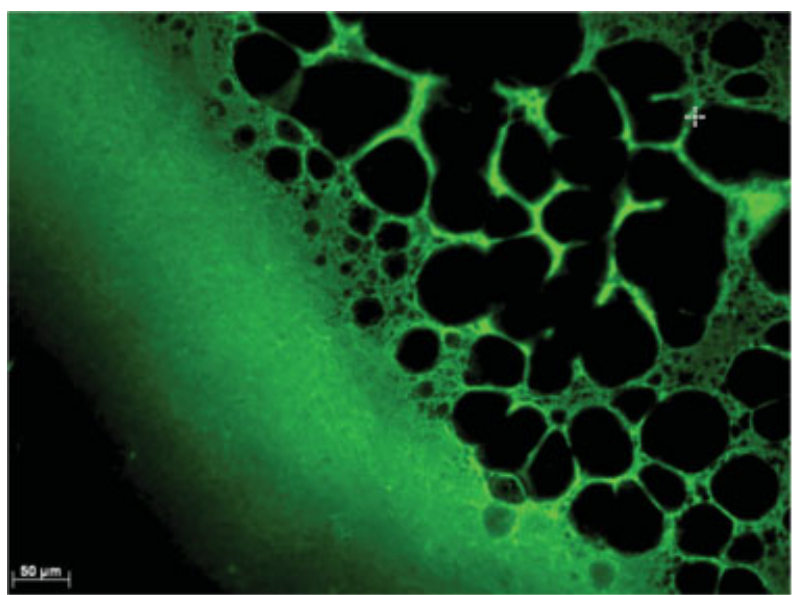

Three weeks after bursal implantation, a transition border between bursal tissue and tendon tissue of the rat was visible. Isolated bursal clusters, now partly interspersed and not sized as compacted tissue, had been found. A high number of GFP-positive cells infiltrated the rotator cuff. MSC migration into the supraspinatus tendon was shown (-Fig. 2).

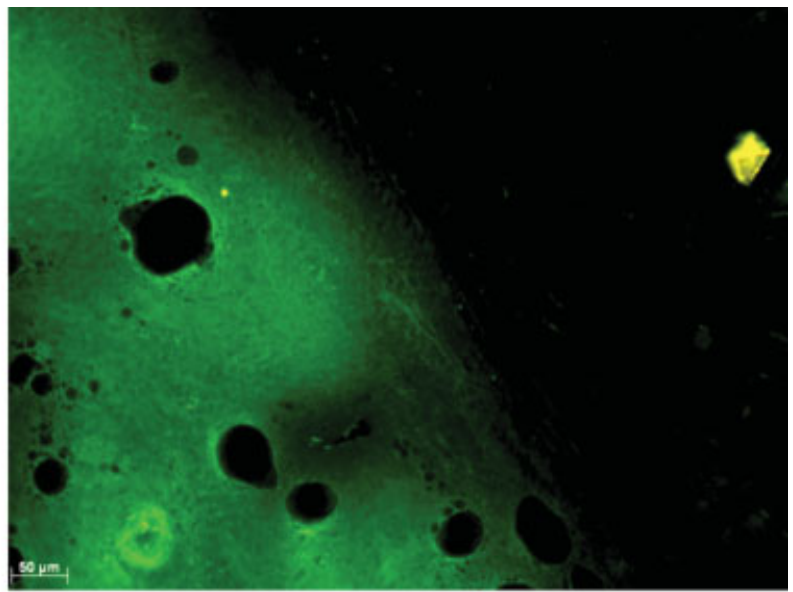

Fig. 1 Bursa implantation after 1 week. On the left side, the transition border between bursal and surrounding tissue is visible. Bursal tissue of green fluorescent protein rat, consisting of fat vacuole and connective tissue, sized as compact tissue. A migration of mesenchymal stem cells is not observed.
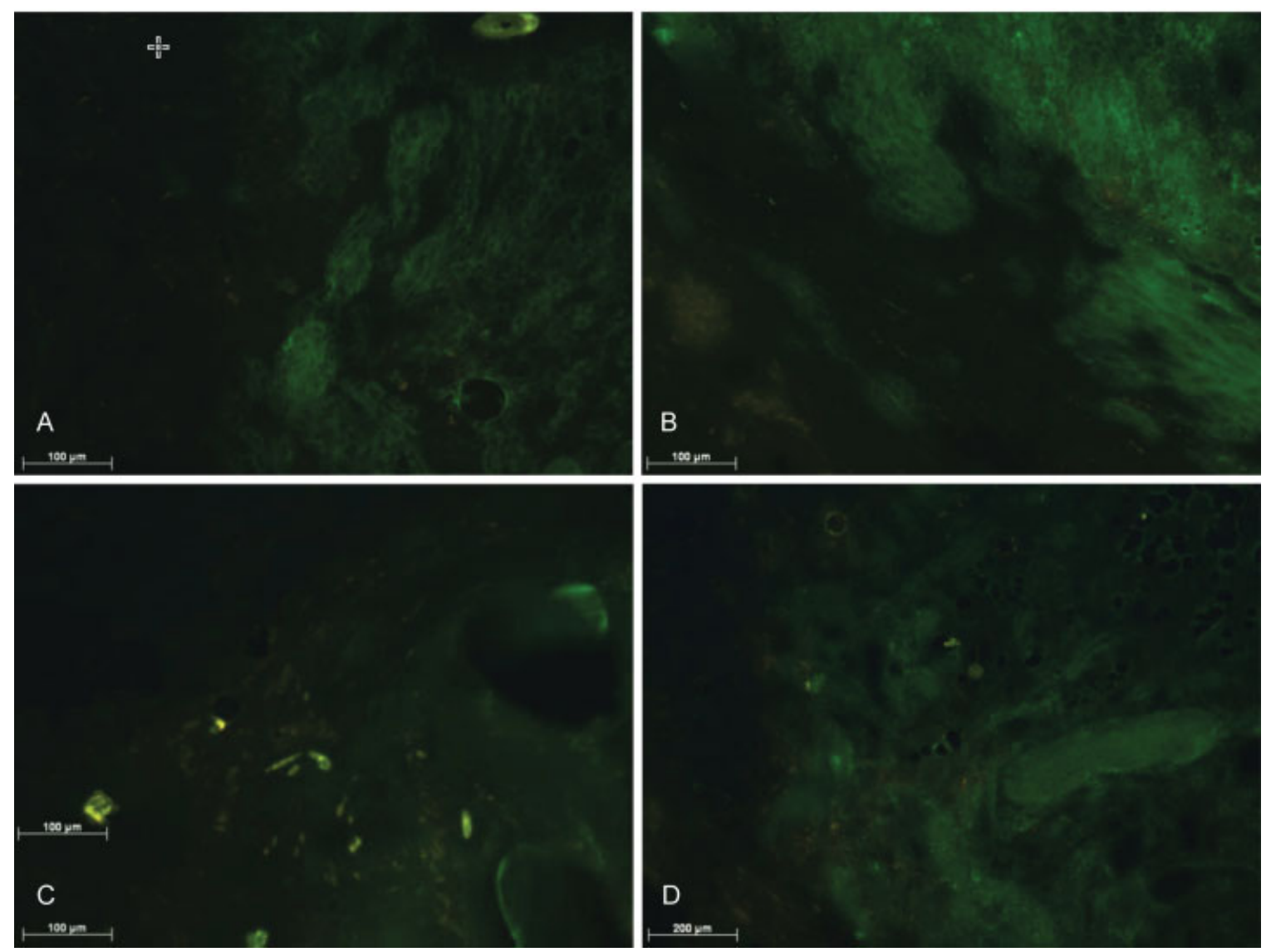

Fig. 2 Three weeks after bursa implantation, transition border between bursal tissue and tendon tissue of the rat is visible. Isolated bursal clusters are demonstrated which now are partly interspersed and not sized as compacted tissue (left picture). Golden cells originate from F344 rat compared with green cells from bursal tissue (GFP rat) at the transition between bursal and tendon/muscle tissue (A-D: magnification x100). 
Six weeks after surgical procedure, the transition borders between bursal tissue and tendon tissue were interfused. The bursal tissue seemed to adhere to the surrounding tissue to form a bursal-tendon-muscle unit (-Fig. 3).

\section{Discussion}

Stem cells with pluripotent abilities are believed to play a major role in tissue healing. ${ }^{23,24}$ As described by Kida et al, ${ }^{23}$ tracking the migration of stem cells in regular tissue is difficult. However, in GFP rats, the green fluorescent protein presented in the cytoplasm and nuclei of all cells (except in hair cells and erythroid cells) can be seen more easily by special histological techniques (-Fig. 4). Descendants of GFP-positive stem cells express GFP signals as long as the cell lives. Therefore, identification can be more easily achieved because of their green fluorescence. Furthermore, their distribution in tissues can be evaluated and inferences can be drawn. ${ }^{23}$

Using different species of rats, studies have shown a lack of autoimmune rejection process after tissue transplantation when transplanting tissues of GFP rats to Fischer rats ${ }^{23,25-27}$ Therefore, GFP rats were used as the donor rat in this investigation.

The results presented in this study supported our hypothesis of the presence of MSCs in bursal tissue of GFP rats. We were also able to show that migration of MSCs from GFP bursal tissue in rats can be observed after surgically induced RCTs.

Effective treatments to enhance tendon repair time as well as the quality of repair are needed. Many studies are currently ongoing examining the issue of the enhancement of the tendon, particularly in rotator cuff repairs to improve surgical procedures, ranging from mini-open to arthroscopic rotator cuff repairs. These clinical trials focus on increasing strength at the repair site to prevent rerupture, to gene therapy, to modification of cytokines and growth factors and tissue engineering with stem cells. 6,27

There is contradictory evidence in the current literature about the effect of the subacromial bursal tissue as part of the rotator cuff. Reports about the presence of MSCs and growth factors are the main topics of several current studies. ${ }^{13-17}$

Some studies investigated the use of stem cells in the repair of tendons, since they have drawn attention for their capability to differentiate into a variety of specialized mesenchymal tissues. These studies demonstrated various degrees of improvement in stem cell-mediated repairs. ${ }^{13-15,23,28-30}$

Daher et $\mathrm{al}^{28}$ performed a study comparing the outcome of tendon healing between regular tendon suture and tendon repair augmented with stem cells after purposeful transection. Achilles tendons of 51 Sprague-Dawley rats were transected and suture-repaired. A biodegradable scaffold seeded with stem cells was placed as an onlay to the defect site in addition to the suture repair in $50 \%$ of the rats. The
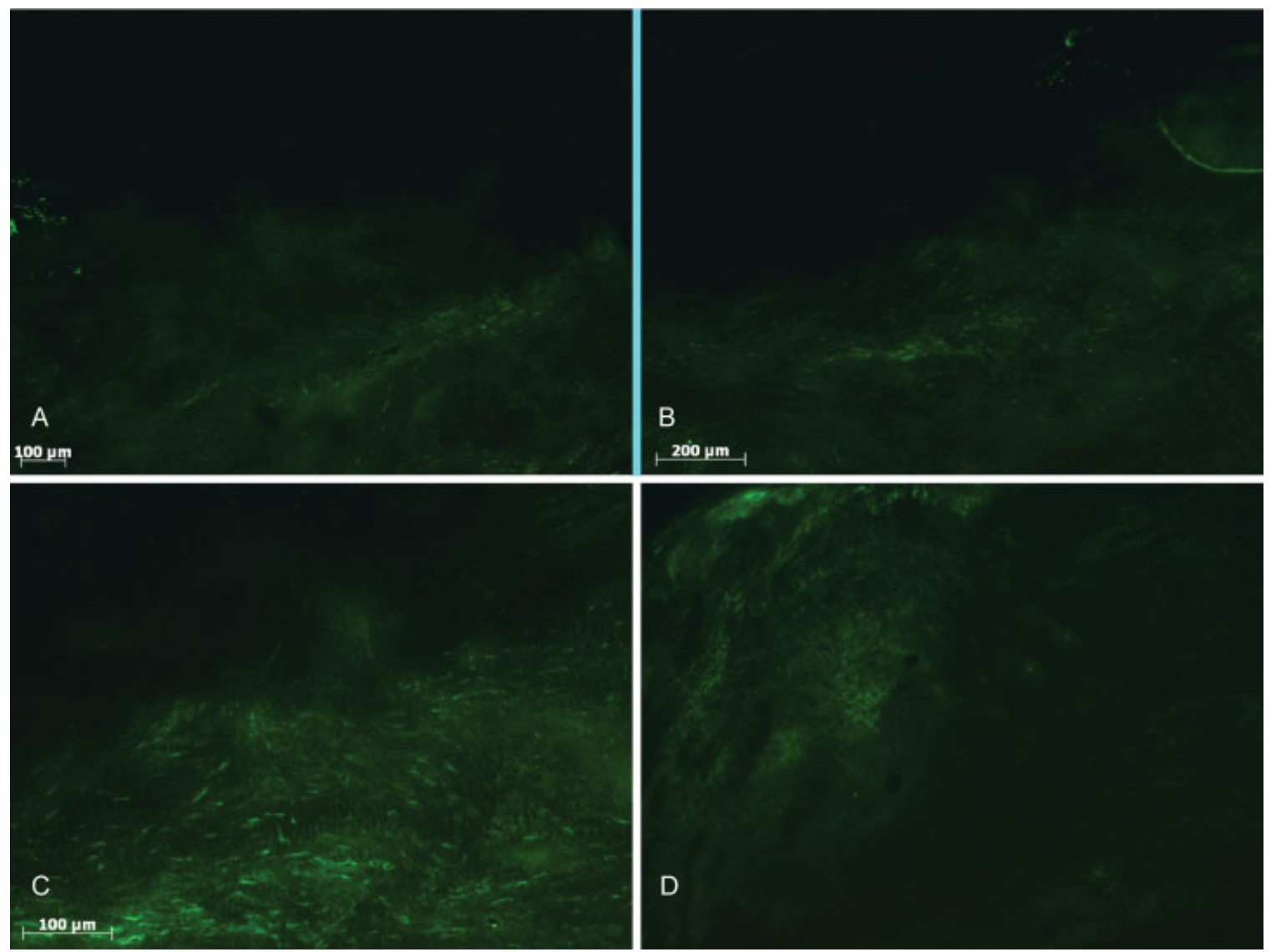

Fig. 3 Six weeks after surgical procedure, the transition borders between bursal tissue and tendon tissue were compounded. The bursal tissue seemed to adhere with surrounding tissue to form a bursal-tendon-muscle unit (A and B: magnification $\times 100 ; C$ and D: magnification $\times 200$ ). 


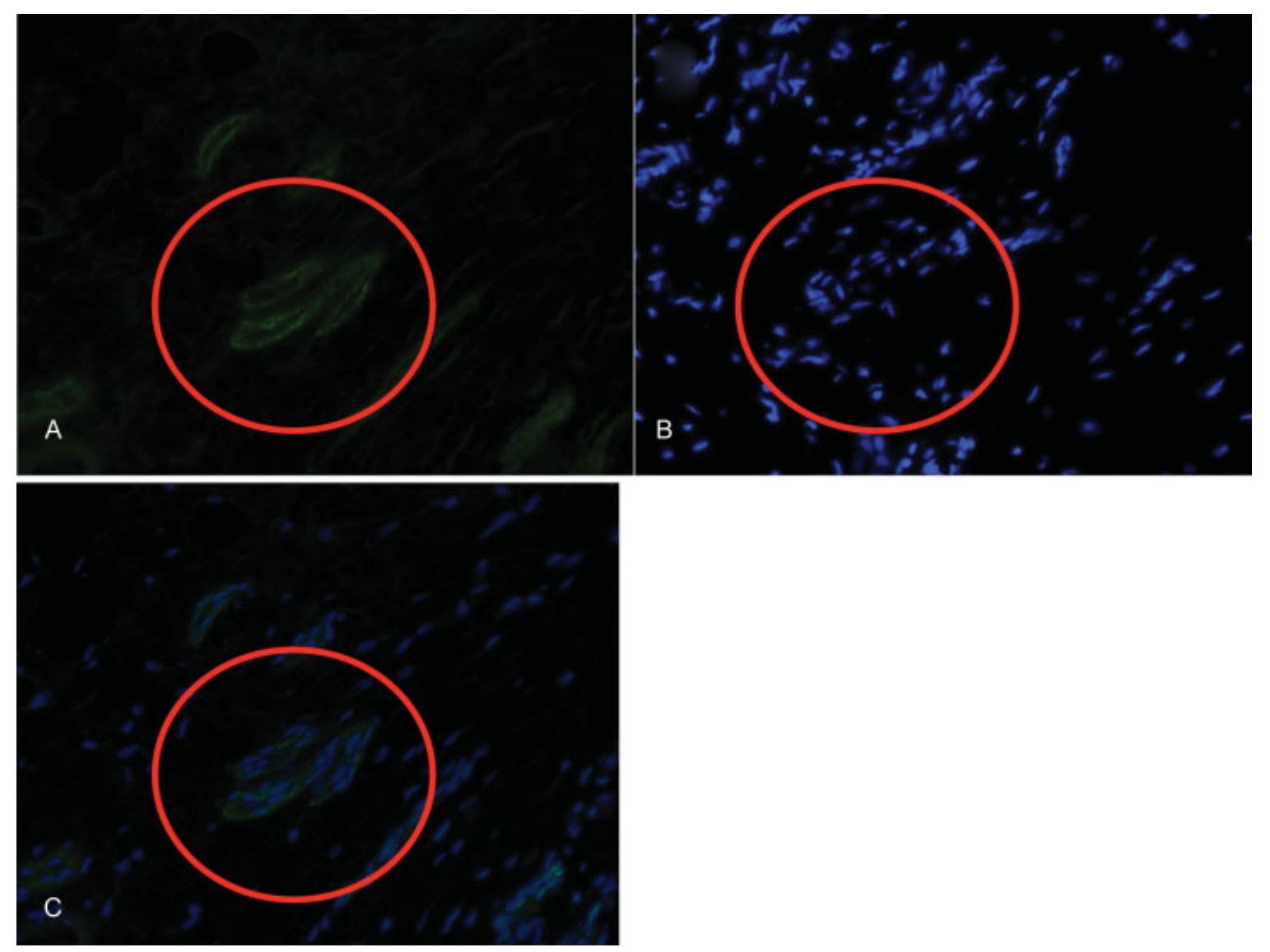

Fig. 4 Evidence of mesenchymal stem cells (MSCs) by staining due to immunostaining (CD73). (A) Proof of vascular tissue with surrounding MSCs. (B) Nuclei-staining in blue. (C) Combination and overlayed pattern of nuclei and MSCs around vascular tissue.

other half of animals was treated with suture alone to serve as control group. The study showed that 4 weeks after surgery both groups showed a continuing healing trend, but the scaffold group exceeded the histological quality of the repaired tissue of the control group. After 6 weeks, the scaffold group had a significant increase in ultimate tensile strength of the tendons and achieved a significantly higher elastic toughness. ${ }^{28}$

In our study, we were able to find evidence of stem cells in bursal tissue migrating into in the repaired rotator cuff and forming bursal cluster patterns after 3 weeks, similar to several studies before. ${ }^{23,27,29}$ After 6 weeks, the bursal tissue and tendon tissue were compounded and bursal tissue seemed to adhere with surrounding tissue to form a bursal-tendon-muscle unit.

Other recent studies were able to show that bone marrow-derived cells, migrated through drilled holes in the humerus footprint, infiltrated the repaired rotator cuff and contributed to postsurgical rotator cuff healing by quicker tissue remodeling. Furthermore, a significantly higher loadto-failure strength was observed, although the release of growth factors was not evaluated. ${ }^{2,3,23}$

The basic cellular tendon repair mechanism is still not fully understood, especially when it comes to the RCTs. Several published studies, which have been made so far, have contributed a significant step in the treatment options for RCTs. Nevertheless, there remains a need for new treatment options to overcome challenges and morbidity associated with acute and chronic tendon injuries. Positive effects of locally present growth factors and especially MSCs are believed to contribute to tissue healing. Therefore, we believe that further investigations should be done to verify this contribution to tendon-tissue healing and to refine treatment options for RCTs.

\section{Limitations}

One limitation of this study is the difference between rat and human rotator cuff healing in chronic and acute tears, especially within intermolecular cell diffusion and migration. Within intermolecular cellular aspects, no evidence for migration of human stem cells from bursal tissue into the surrounding tissue could be attained. In addition, the quality characteristics between human and rat stem cells might be completely different. Another limitation is the lack of cell counting of GFP cells within the bursal tissue. Furthermore, only five animals had been used for histological analysis. Finally, rotator cuff healing in rats is more likely to occur and happens faster in comparison to humans.

In conclusion, we were able to monitor MSC migration from bursal tissue into surrounding tendon tissue and 
muscle tissue in a rotator cuff repair animal model. MSCs from bursal tissue infiltrate the repaired rotator cuff and may contribute to the healing progress of the tendon tissue.

\section{Funding}

All the authors report grants from Munich Working Group for sponsorship of orthopaedic and trauma surgery research, during the conduct of the study. This study was funded by the Munich Working Group for sponsorship of orthopaedic and trauma surgery research at the LudwigMaximilian-University e.V (Münchner Arbeitsgemeinschaft zur Förderung der Orthopädischen und Unfallchirurgischen Forschung an der LMU e.V [MAOUF], a nonprofit organization) 2014.

\section{Conflict of Interest}

None.

\section{References}

1 Denaro V, Ruzzini L, Longo UG, et al. Effect of dihydrotestosterone on cultured human tenocytes from intact supraspinatus tendon. Knee Surg Sports Traumatol Arthrosc 2010;18(07):971-976

2 Ficklscherer A, Loitsch T, Serr M, et al. Does footprint preparation influence tendon-to-bone healing after rotator cuff repair in an animal model? Arthroscopy 2014;30(02):188-194

3 Ficklscherer A, Scharf M, Hartl TK, et al. Tissue characteristics in tendon-to-bone healing change after rotator cuff repair using botulinumneurotoxin A for temporary paralysis of the supraspinatus muscle in rats. Connect Tissue Res 2014;55(02):140-146

4 Franceschi F, Longo UG, Ruzzini L, et al. Circulating substance P levels and shoulder joint contracture after arthroscopic repair of the rotator cuff. Br J Sports Med 2008;42(09):742-745

5 Galatz LM, Ball CM, Teefey SA, Middleton WD, Yamaguchi K. The outcome and repair integrity of completely arthroscopically repaired large and massive rotator cuff tears. J Bone Joint Surg Am 2004;86-A(02):219-224

6 Bishop J, Klepps S, Lo IK, Bird J, Gladstone JN, Flatow EL. Cuff integrity after arthroscopic versus open rotator cuff repair: a prospective study. J Shoulder Elbow Surg 2006;15(03):290-299

7 Ficklscherer A, Hartl TK, Scharf M, et al. Effects of selective paralysis of the supraspinatus muscle using botulinum neurotoxin a in rotator cuff healing in rats. J Orthop Res 2013;31(05): 716-723

8 Fuchs B, Gilbart MK, Hodler J, Gerber C. Clinical and structural results of open repair of an isolated one-tendon tear of the rotator cuff. J Bone Joint Surg Am 2006;88(02):309-316

9 Jost B, Zumstein M, Pfirrmann CW, Gerber C. Long-term outcome after structural failure of rotator cuff repairs. J Bone Joint Surg Am 2006;88(03):472-479

10 Meyer M, Klouche S, Rousselin B, Boru B, Bauer T, Hardy P. Does arthroscopic rotator cuff repair actually heal? Anatomic evaluation with magnetic resonance arthrography at minimum 2 years follow-up. J Shoulder Elbow Surg 2012;21(04):531-536

11 Hettrich CM, Rodeo SA, Hannafin JA, Ehteshami J, Shubin Stein BE. The effect of muscle paralysis using Botox on the healing of tendon to bone in a rat model. J Shoulder Elbow Surg 2011;20(05):688-697
12 Longo UG, Berton A, Papapietro N, Maffulli N, Denaro V. Biomechanics of the rotator cuff: European perspective. Med Sport Sci 2012;57:10-17

13 Cheung EV, Silverio L, Sperling JW. Strategies in biologic augmentation of rotator cuff repair: a review. Clin Orthop Relat Res 2010; 468(06):1476-1484

14 Nourissat G, Diop A, Maurel N, et al. Mesenchymal stem cell therapy regenerates the native bone-tendon junction after surgical repair in a degenerative rat model. PLoS One 2010;5(08):e12248

15 Rodeo SA, Potter HG, Kawamura S, Turner AS, Kim HJ, Atkinson BL. Biologic augmentation of rotator cuff tendon-healing with use of a mixture of osteoinductive growth factors. J Bone Joint Surg Am 2007;89(11):2485-2497

16 Uhthoff HK, Sarkar K. Surgical repair of rotator cuff ruptures. The importance of the subacromial bursa. J Bone Joint Surg Br 1991;73 (03):399-401

17 Utsunomiya H, Uchida S, Sekiya I, Sakai A, Moridera K, Nakamura T. Isolation and characterization of human mesenchymal stem cells derived from shoulder tissues involved in rotator cuff tears. Am J Sports Med 2013;41(03):657-668

18 Soslowsky LJ, Carpenter JE, DeBano CM, Banerji I, Moalli MR. Development and use of an animal model for investigations on rotator cuff disease. J Shoulder Elbow Surg 1996;5(05):383-392

19 Derwin KA, Baker AR, Iannotti JP, McCarron JA. Preclinical models for translating regenerative medicine therapies for rotator cuff repair. Tissue Eng Part B Rev 2010;16(01):21-30

20 Ackermann PW, Spetea M, Nylander I, Ploj K, Ahmed M, Kreicbergs A. An opioid system in connective tissue: a study of Achilles tendon in the rat. J Histochem Cytochem 2001;49(11):1387-1395

21 Franchi M, Fini M, Quaranta M, et al. Crimp morphology in relaxed and stretched rat Achilles tendon. J Anat 2007;210(01):1-7

22 Rufai A, Ralphs JR, Benjamin M. Ultrastructure of fibrocartilages at the insertion of the rat Achilles tendon. J Anat 1996;189(Pt 1):185-191

23 Kida Y, Morihara T, Matsuda K, et al. Bone marrow-derived cells from the footprint infiltrate into the repaired rotator cuff. J Shoulder Elbow Surg 2013;22(02):197-205

24 Koike Y, Trudel G, Uhthoff HK. Formation of a new enthesis after attachment of the supraspinatus tendon: a quantitative histologic study in rabbits. J Orthop Res 2005;23(06):1433-1440

25 Iwata Y, Morihara T, Tachiiri H, et al. Behavior of host and graft cells in the early remodeling process of rotator cuff defects in a transgenic animal model. J Shoulder Elbow Surg 2008;17(1, Suppl): 101S-107S

26 Kobayashi M, Watanabe N, Oshima Y, Kajikawa Y, Kawata M, Kubo $\mathrm{T}$. The fate of host and graft cells in early healing of bone tunnel after tendon graft. Am J Sports Med 2005;33(12):1892-1897

27 Okabe M, Ikawa M, Kominami K, Nakanishi T, Nishimune Y. ‘Green mice' as a source of ubiquitous green cells. FEBS Lett 1997;407 (03):313-319

28 Daher RJ, Chahine NO, Razzano P, Patwa SA, Sgaglione NJ, Grande DA. Tendon repair augmented with a novel circulating stem cell population. Int J Clin Exp Med 2011;4(03):214-219

29 Gulotta LV, Kovacevic D, Ehteshami JR, Dagher E, Packer JD, Rodeo SA. Application of bone marrow-derived mesenchymal stem cells in a rotator cuff repair model. Am J Sports Med 2009;37(11): 2126-2133

30 Randelli PS, Arrigoni P, Cabitza P, Volpi P, Maffulli N. Autologous platelet rich plasma for arthroscopic rotator cuff repair. A pilot study. Disabil Rehabil 2008;30(20-22):1584-1589 